\title{
Biodegradation of phenol by aspergillus Niger
}

\author{
Mrs.Ch.supriya ${ }^{1}$, Deva neehar ${ }^{2}$ \\ Department of pharmaceutical biotechnology, Nirmala College of pharmacy \\ Atmakur (vil), Mangalagiri (Md), Guntur (Dt), Andhra Pradesh
}

\begin{abstract}
Phenolic compounds are hazardous pollutants that are toxic to the natural ecosystem at very low concentration Biodegradation is the process by which organic substances are broken down into smaller compounds by the catalytic activity of living microbial organisms. The use of microbes as catalysts in the biodegradation of phenolic compounds has advanced significant in the recent decades. Biodegradation of phenol involves the complete mineralization of phenolic compounds to simple compounds like $\mathrm{CO}_{2}, \mathrm{H}_{2} \mathrm{O}, \mathrm{NO}_{3}$ .we studied the biodegradation performance of phenol by using free cells of Aspergillus niger under different temperature, $\mathrm{pH}$, concentration, and at different incubation periods under the aerobic conditions .
\end{abstract}

KEYWORDS: Aspergillus niger, Biodegradation, mineralization, phenol, Toxicity .

\section{INTRODUCTION}

Due to rapid industrialization and economic development, many pharmaceutical and chemical industries are releasing their effluents in to natural ecosystem and they are inhibiting the sunlight penetration and reducing the photosynthetic activity of acquatic system.Many of these aromatic compounds are toxic to the living system and their presence in the aquatic and terrestrial habitats often have serious ecological consequences. Among all these aromatic compounds phenol is the most toxic compound and it can persist in the environmentfor longtime due to its long range transportation, bioaccumulation in human and animal tissue and biomagnification in food chain. Biodegradation is emerging as most ideal technology for removing phenolic pollutants from the environment by the action of microbes restoring contaminated sites and preventing further pollution ${ }^{[1]}$. Phenols are introduced in the environment in the waste water stream of several industrial operations, through its use as antimicrobial agent or as by-product of other pharmaceutical industries, or even waste incineration and as degradation product of other chlorinated xenobiotics ${ }^{[2]}$. Phenol pollution is associated with pulp mills, coal mines, refineries, wood preservation plants and various chemical industries as well as their waste waters ${ }^{[3]}$. Natural sources of phenol include forest fire, natural run off from urban area where asphalt is used as the binding material and natural decay of ligno cellulosic material. The presence of phenol in water imparts carbolic odor to receiving water bodies and can cause toxic effects on aquatic flora and fauna ${ }^{[4]}$. Phenols are toxic to human beings and affect several biochemical functions ${ }^{[5]}$. Phenol is also a priority pollutant and is included in the list of EPA (1979).

Inspite of phenolic toxic properties,a number of micro-organisms can utilize phenol under aerobic conditions as sources of carbon and energy ${ }^{[6]}$. Biodegradation technologies most often take advantage of the ability of various bacteria to clean the environment bioremediation is constantly expanding. Fungi are famous for their wide incidence and the outstanding capacity of degrading complex and inert natural products like lignin, chitin and cellulose. Fungi adopt more easily than bacteria and are capable to grow in extreme conditions, like nutrient deficiency, low $\mathrm{pH}$, limited water supply, etc. ${ }^{[7]}$ And not on the least, there comes the ability of fungi to survive in the presence of various xenobiotics that turn to be toxic to a number of other microorganisms. Metabolism of aromatic compounds, and i.e phenol and its derivatives, has been extensively researched in prokaryotic micro organisms ${ }^{[8] .}$ Particularly huge information have been collected about bacterial species of Pseudomonas genus ${ }^{[9]}$.Number of individual representatives of the genera Candida, Rodotorula and Trichosporon, which are capable of metabolizing aromatic compounds. ${ }^{[10,11]}$ The specific enzymes responsible for biodegradation occupy an important place in these investigations.From Penicillium, Aspergillus, Fusarium, Graphium and Phanerochaete genera to disintegrate aromatic compounds. In 15 strains belonging to Fusarium, Aspergillus, Penicillium and Graphium genera the presence of phenol hydroxylase and catechol 1,2dioxygenase activity in cells cultivated on a phenol-containing medium has been confirmed. These findings demonstrate that catechol oxidation follows the ortho - pathway of breaking the aromatic ring 


\section{MECHANISM OF PHENOL DEGRADATION:}

The enzymatic machinery is well suited for the degradation of phenol.Generally aromatic compounds are broken down by natural bacteria and fungi. It showed that the micro organisms are capable of degrading phenol through the action of variety of enzymes.These enzymes include oxygenase, hydoxylase, peroxidases, and oxidases. Oxygenase includes monoxygenases and dioxygenase,the critical step in the metabolism of aromatic compounds is the destruction of the resonance structure by hydroxylation and fission of the benzoid ring which is achieved by dioxygenase-catalysed reactions in the aerobic systems.Based on the substrate that is attacked by the ring cleaving enzyme dioxygenase,the aromatic metabolism can be grouped as catechol pathway, The ring fission is catalysed by an ortho cleavage enzyme,catechol 1,2 dioxygenase or by a meta cleavage enzyme catechol 2,3 dioxygenase,where the product of ring fission is a cis-muconic acid for the former and 2-hydro cis muconic semi aldehyde for the latter. Catechols are cleaved either by ortho-fission (intradiol, that is, carbon bond between two hydroxyl groups) or by a meta-fission (extra diol, that is, between one of the hydroxyl groups and a non-hydroxylated carbon). Thus the ring is opened and the open ring is degraded ${ }^{[12]}$. There are many reports on phenol hydroxylase and catechol 2,3 dioxygenase involved in the biodegradation of phenol. The mechanism by which polyphenol oxidase catalyses the conversion of monophenols to O-quinones involves the hydroxylation of monophenols followed by dehydrogenation to form $\mathrm{O}$-quinones. These quinones undergo spontaneous nonenzymatic polymerization in water, eventually forming water insoluble polymers which can be separated from water by filtration. The mechanism of phenol biodegradation mainly takes place through the following path ways.

\subsubsection{Meta path way of phenol degradation}

\subsubsection{Ortho path way of phenol degradation}

\section{Equation 1.1.1.Meta pathway of phenol degradation:}

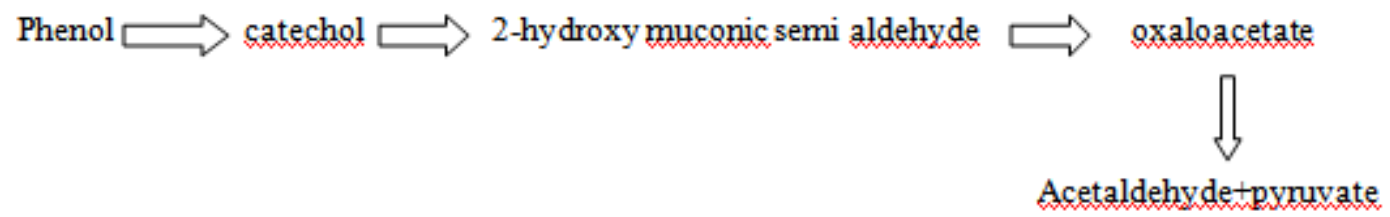

Equation 1.1.2: Ortho path way of phenol degradation:

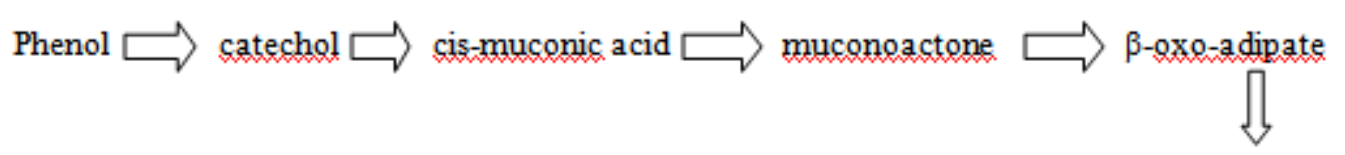

\section{TCA}

1.2. STRAIN: In the present study we use Aspergillus Niger (ATCC-16404) strain is used to degrade the phenol. Aspergillus Niger is a fungus and one of the most common species of the genus Aspergillus. It causes a disease called black mold on certain fruits and vegetables such as grapes, onions, and peanuts, and is a common contaminant of food. It is ubiquitous in soil and is commonly reported from indoor environments, where its black colonies can be confused with those of Stachybotrys (species of which have also been called "black mould")

\section{MATERIALS AND METHODS}

2.1. Chemicals: All the chemicals used in the present study were of pure quality grade. All the media constituents were of pure quality grade, and analytical grade.The phenol degradation activity was measured by ELICO uv-visible spectrometer in the pharmaceutical analysis laboratory. 
2.2. PREPARATION OF INOCULUM: In the present study the selected strain i.e. Aspergillus Niger [ATCC16404] was collected from National Collection of Industrial Microorganisms(NCIM,pune). The isolates were maintained on potato dextrose agar slants. Generally $72 \mathrm{hrs}$ old cultures were used for the preparation of the inoculum. The strain was propagated in a PDA agar slants and maintain at $35^{\circ} \mathrm{c}$ for 5 days until sporulation takes place. The slant which shows the maximum growth of fungal organism was used in the phenol degradation study.

\subsection{COMPONENTS OF INOCULUM MEDIUM:}

\begin{tabular}{|c|c|}
\hline INGREDIANTS & {$[\% \mathrm{~W} / \mathrm{V}]$} \\
\hline Potatoes & $20 \mathrm{gm}$ \\
\hline Dextrose & $2 \mathrm{gm}$ \\
\hline Agar & $2.5 \mathrm{gm}$ \\
\hline Distilled water & $100 \mathrm{ml}$ \\
\hline $\mathrm{pH}$ & 5 to5.5 \\
\hline
\end{tabular}

\section{EXPERIMENT}

The phenol degradation experiments were carried out by taking the initial concentration of 100mg/l phenol with $5 \mathrm{mg}$ mycelial mass of Aspergillus Niger. Prepare the potato dextrose agar medium and take in to conical flask. Now the flasks containing the $250 \mathrm{ml}$ of inoculated medium (PDAmedium) were added with $100 \mathrm{mg} / \mathrm{l}$ of phenol and it was inoculated with $5 \mathrm{mg}$ mycelia of aspergillus Niger.Now the phenol containing inoculated medium is incubate in orbital shaker incubator at $30^{\circ} \mathrm{c}$ and $200 \mathrm{rpm}$ for $78 \mathrm{hrs}$ under aerobic conditions.Samples were withdrawn at regular intervals for phenol determination.Take the sample from the rotary shaker flask and it is subjected to the centrifugation at $1200 \mathrm{rpm}$ for $15 \mathrm{~min}$. Then collect the supernant from the centrifuged media and further subjected to the Phenol determination studies

3.1.Phenol determination : For the determination of phenol content,the folin-ciocalteau phenol reagent was used.To the $0.1 \mathrm{ml}$ of supernant liquid add $0.1 \mathrm{ml}$ of $2 \%$ of $\mathrm{Na}_{2} \mathrm{CO}_{3} 0.1 \mathrm{ml}$ of Folin- ciocalteau reagent and add $2 \mathrm{ml}$ of distilled water.Then it is kept aside for $60 \mathrm{~min}$ at $20^{\circ} \mathrm{c}$.Then the absorbance was measured at $725 \mathrm{~nm}$ against a distilled water and reagent blank ${ }^{[13] .}$

\section{RESULTS AND DISCUSSIONS}

4.1. Effect of temperature on the biodegradation of phenol: To determine the effect of temperature the experiments were carried out at different temperatures such as $25^{\circ} \mathrm{c}, 35^{\circ} \mathrm{c}, 40^{\circ} \mathrm{c}, 50^{\circ} \mathrm{c}$ and $60^{\circ} \mathrm{c}$ at $\mathrm{pH} 4.5$ for 120 hrs of incubation period. The data shows that there was maximum phenol degradation takes place at room temperature of $35^{\circ} \mathrm{c}$ and on further increase in temperature The rate of biodegradation decreases because the catalytic activity of the enzymes is starts to decrease beyond that temperature. So, the optimum temperature for the maximum enzymatic activity is $35^{\circ} \mathrm{c}$. The results were tabulated in TABLE5.1 and in Fig5.1.1.

4.2. Effect of ph on the biodegradation of phenol: While optimizing the initial $\mathrm{pH}$, the medium $\mathrm{pH}$ was varied such as Acidic [5.5], Basic [9-10] \&Neutral [7.2] at $35^{\circ} \mathrm{c}$ and for $120 \mathrm{hrs}$. The results show that there was maximum Phenolic degradation occurs at neutral $\mathrm{pH}$ due to maximum utilization of carbon source..At acidic or basic $\mathrm{pH}$ there is reduction in phenolic degradation due to the fact at that culture utilize less carbon source. The results were tabulated in TABLE5.2 and in Fig5.2.1.

4.3. Effect of incubation period on the biodegradation of phenol: To determine the effect of incubation period the experiments were carried at different incubation periods such as 24hrs, 48hrs, $72 \mathrm{hrs}$ and $120 \mathrm{hrs}$ at $35^{\circ} \mathrm{c}$ and $\mathrm{pH} 4.5$. The results shows that maximum Phenolic degradation was occured at $120 \mathrm{hrs}$ due to maximum utilization of phenol after that it starts to decrease due to saturation of active sites of utilizing enzymes. The results were tabulated in TABLE5.3 and in Fig5.3.1.

4.4. Effect of concentration of phenol on the phenol degradation: To determine the effect of concentration experiments were carried at different concentrations of phenol such as $100 \mathrm{mg} / \mathrm{l}, 200 \mathrm{mg} / \mathrm{l}, 300 \mathrm{mg} / \mathrm{l}, 400 \mathrm{mg} / \mathrm{l}$ and $500 \mathrm{mg} / \mathrm{l}$ at $35^{\circ} \mathrm{c} \mathrm{pH} 4.5$ for $120 \mathrm{hrs}$ of incubation period.Then the results were tabulated and it shows that maximum phenolic degradation was observed at $300 \mathrm{mg} / \mathrm{lit}$ this due to the fact that the phenol degrading enzymes activity is optimum at this concentration. The results were tabulated in TABLE5.4 and in Fig5.4.1. 


\section{TABLES AND FIGURES}

TABLE 5.1. EFFECT OF TEMPERATURE

\begin{tabular}{|c|c|c|c|}
\hline S.NO & TEMPERATURE & INITIAL ABSORBANCE & FINAL ABSORBANCE \\
\hline 1 & $25^{\circ} \mathrm{c}$ & 0.681 & 0.567 \\
\hline 2. & $35^{\circ} \mathrm{c}$ & 0.681 & 0.547 \\
\hline 3. & $40^{\circ} \mathrm{c}$ & 0.681 & 0.597 \\
\hline 4. & $50^{\circ} \mathrm{c}$ & 0.681 & 0.614 \\
\hline 5. & $60^{\circ} \mathrm{c}$ & 0.681 & 0.642 \\
\hline
\end{tabular}

TABLE 5.2. EFFECT OF PH

\begin{tabular}{|c|c|c|c|}
\hline S.NO & PH & INITIAL ABSORBANCE & FINAL ABSORBANCE \\
\hline 1. & Acidic & 0.507 & 0.590 \\
\hline 2. & Basic & 0.602 & 0.675 \\
\hline 3. & Neutral & 0.677 & 0.658 \\
\hline
\end{tabular}

TABLE5.3. EFFECT OF INCUBATION PERIOD

\begin{tabular}{|c|c|c|c|}
\hline S.NO & INCUBATION PERIOD & INITIAL ABSORBANCE & FINAL ABSORBANCE \\
\hline 1 & $24 \mathrm{hrs}$ & 0.680 & 0.126 \\
\hline 2 & $48 \mathrm{hrs}$ & 0.680 & 0.122 \\
\hline 3 & $72 \mathrm{hrs}$ & 0.680 & 0.117 \\
\hline 4 & $96 \mathrm{hrs}$ & 0.680 & 0.102 \\
\hline
\end{tabular}

TABLE5.4. EFFECT OF CONCENTRATION

\begin{tabular}{|c|c|c|c|}
\hline S.NO. & CONCENTATION[mg/l] & INITIAL ABSORBANCE & FINAL ABSORBANCE \\
\hline 1 & 100 & 0.541 & 0.314 \\
\hline 2 & 200 & 0.635 & 0.222 \\
\hline 3 & 300 & 0.681 & 0.123 \\
\hline 4 & 400 & 0.711 & 0.155 \\
\hline 5 & 500 & 0.717 & 0.136 \\
\hline
\end{tabular}




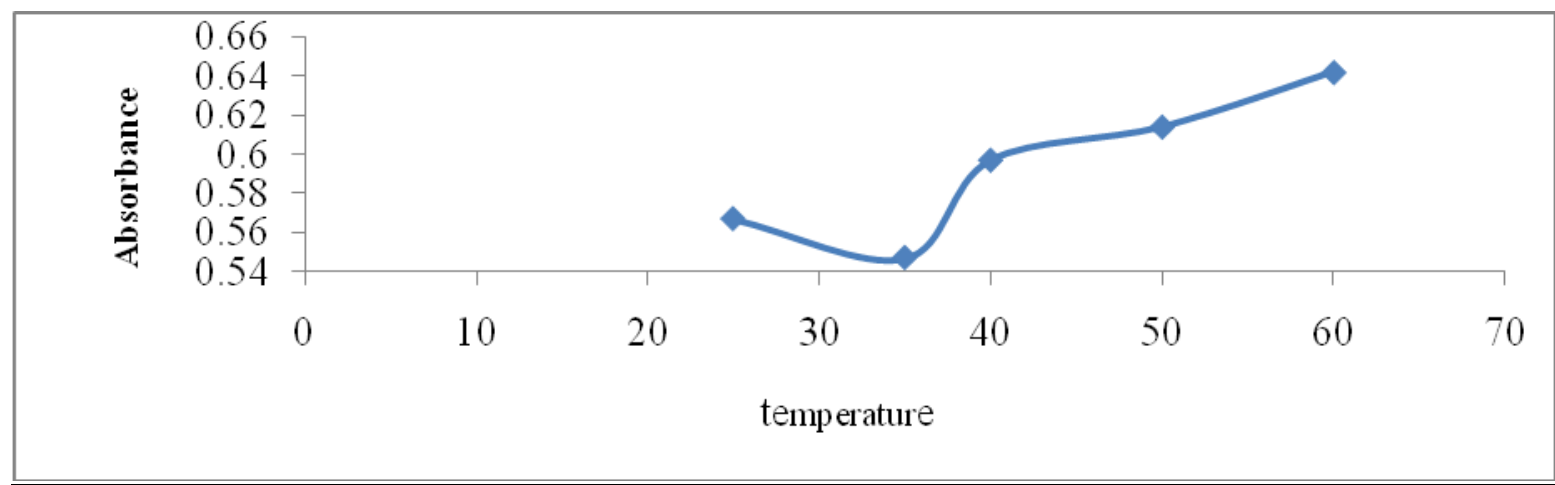

Figure 5.1.1: Biodegradation of phenol by A.niger at different temperatures

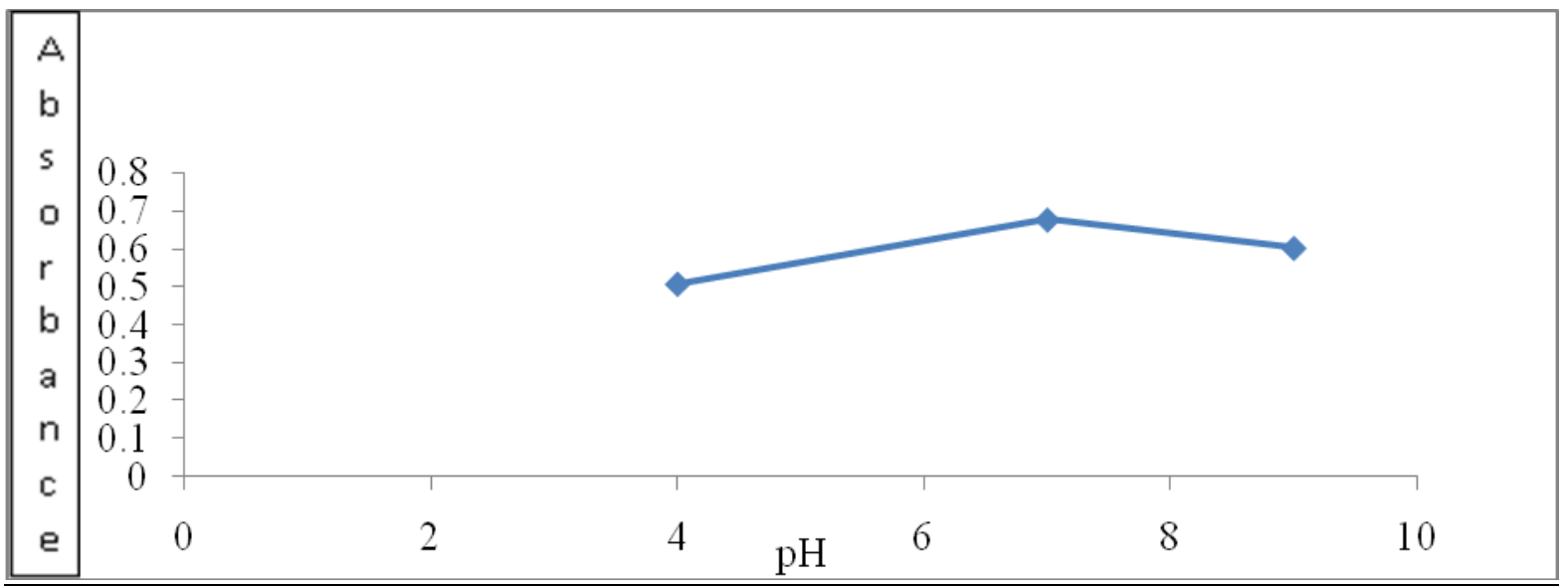

Figure 5.2.1: Biodegradation of phenol by A.niger at different $\mathrm{pH}$

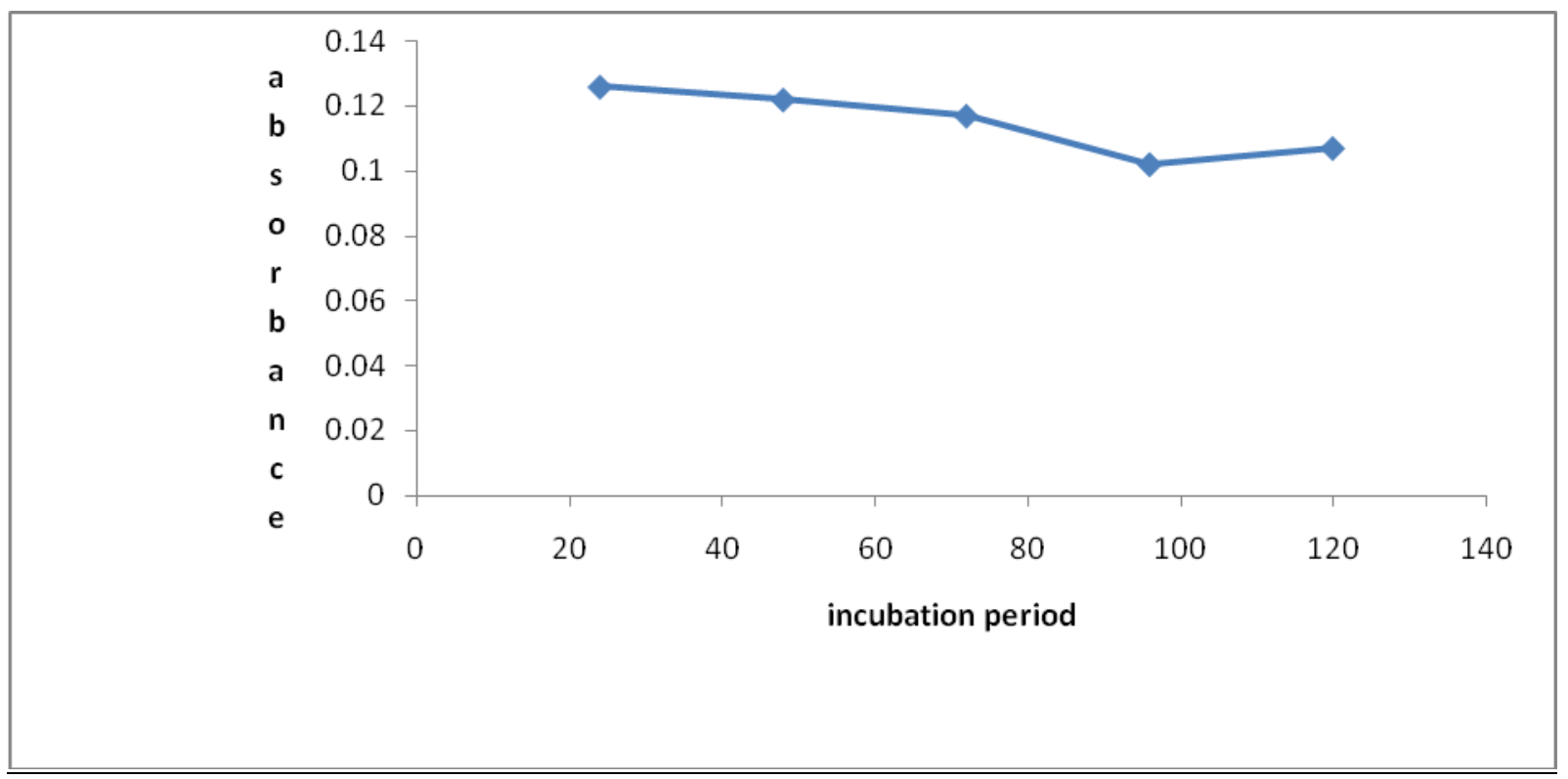

Figure.5.3.1: Biodegradation of phenol by A.niger at different incubaion periods. 


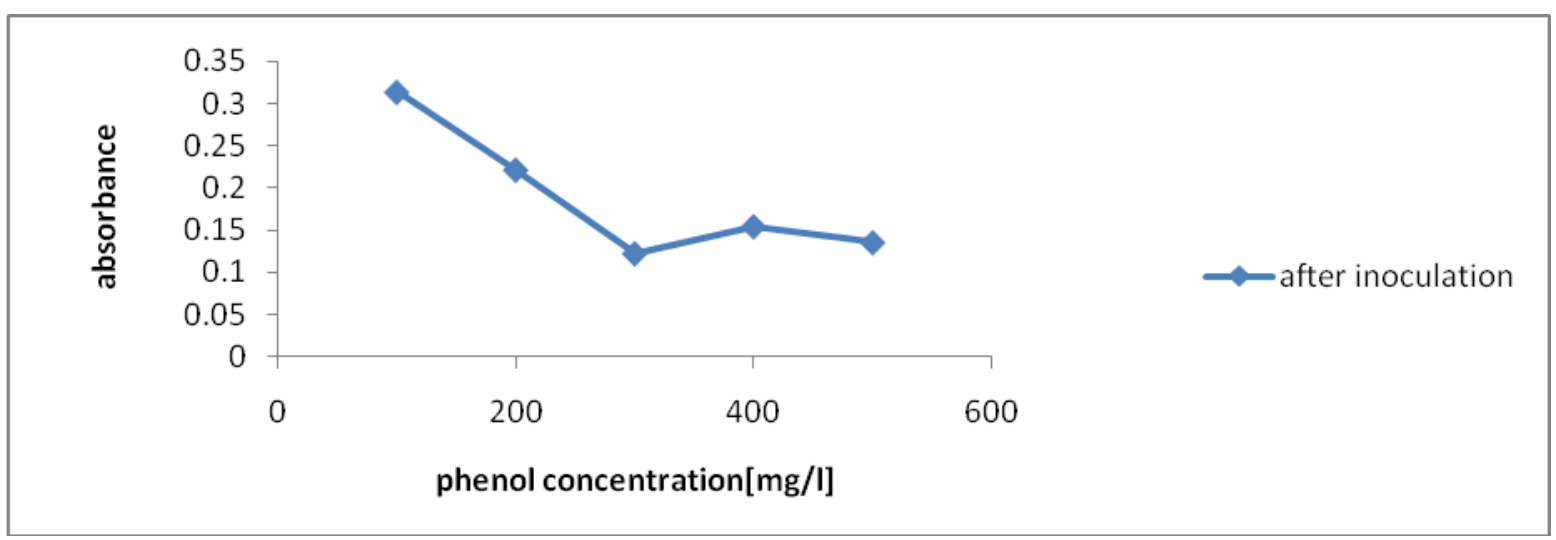

Figure5..4.1: Biodegradation of phenol by A.niger at different biomass concentrations.

\section{CONCLUSIONS}

From the above study it was concluded that as the phenol is one of the major effluent of so many chemical industries and as it is causing lethal effect to the human system. so, it has to be treated to control its toxic effects. So we have chosen a simple, cost effective method known as biodegradation to degrade the phenol and other effluents to protect the environment. In the present study we used one fungal culture as a biosorbant to degrade the phenol and we fixed the optimum parameters for the maximum degradation of phenol.

From the above study it was concluded that

- The phenol degradation by Aspergillus Niger (ATCC-16404) was maximum at a room temperature of $35^{\circ} \mathrm{c}$.

- $\quad$ The phenol degradation by Aspergillus Niger (ATCC-16404) was maximum at neutral pH of 7.2.

- $\quad$ The phenol degradation by Aspergillus Niger (ATCC-16404) was maximum Incubation period of $120 \mathrm{hrs}$.

- The phenol degradation by Aspergillus Niger (ATCC-16404) was maximum at 300mg/lit of phenol concentration.

Biodegradation is one of the useful and highly effective method to protect the global environment. In nature all the plant, animal and microbial sources shows the biosorbant property and hence we may choose any waste material to control this toxic effluentsof various industries..At present the chances of pollution is very much high with the toxic effluents of different chemical industries such as pharmaceutical, chemical, leather, dyes etc. So, we may protect our environment by this biosorption method.

\section{ACKNOWLEDGEMENTS}

The author is very much thankful to the management to provide the facilities towards the publication.

\section{REFRENCES}

[1] Atlas RM, Bartha R (1998). In Microbial Ecology: Fundamentals and applications. 4th Edition.Benjamin Cummings Science Publishing California.

[2] Wackett LP, Hershberger DC (2001). In Biocatalysis and Biodegradation, Microbial transformations of organic compounds. ASM press, Am. Soc.Microbiol. Washington DC.

[3] Paula M, Van schei, Young LY (1998). Isolation and Characterization of phenol degrading denitrifying bacteria. Appl. Environ. Microbiol 64(7):2432-2438.

[4] Ghadhi SC, Sangodkar UMX (1995). Potentials of Pseudomonas cepacia PAA in bioremediation of aquatic wastes containing phenol. Proceedings of National symposium frontiers in applied and environmental microbiology, 11-13, Dec. Cochin.

[5] Nuhoglu A, Yakin B (2005). Modelling of phenol removal in a batch reactor. Proc. Biochem. 40: 233-239.

[6] Chen KN, Chen MJ, Lin CW (2006). Optimal combination of the encapsulating materials for probiotic microcapsules and its experimental verification (R 1). J. Food Eng. 76: 313-32)

[7] Atagana, H. World J. Microb.Biotechnol. 20: 845-849 (200).

[8]. Watanabe, K, Teramoto, H., Futamata, H., and Harayama, S. Appl Environ Microbiol 64: 4396-4402 (1998).

[9]. Seker, S., Beyenal, H., Salih B., Tomas A. Appl. Microbiol. Biotechnol. 47: 610-614 (1997).Stoilova et al. EJEAFChe, 7 (12), 2008. [2625-2633]

[10]. Cerniglia, C., and Crow, S. Arch. Microbiol. 129: 9-13 (1981).

[11]. Mac Gillivray, A., Shiaris, M. Appl Environm. Microb. 59:1613-1618 (1993). 
[12]. Cerniglia CE (1984). Microbial transformations of aromatic hydrocarbons. In Petroleum Microbiology: Atlas RM (ed). Macmillon, NewYork, 99-128.

[13]. Leonard D, Lindly NA (1999a). Growth of Ralstonia eutropha on inhibitory concentration of phenol: Diminished Growth can be attributed to hydrophilic perturbation of Phenol hydroxylase activity. Enzyme Microbial Technol. 25: 271-277. 